\title{
REVIEW
}

\section{Epigenetic arginine methylation in breast cancer: emerging therapeutic strategies}

\author{
Shu-Ching M Wang, Dennis H Dowhan and George E O Muscat \\ Cell Biology and Molecular Medicine Division, The University of Queensland, Institute for Molecular Bioscience, St Lucia, Australia
}

Correspondence should be addressed to S-C M Wang or G E O Muscat: shu-ching.wang@uq.edu.au or g.muscat@uq.edu.au

\begin{abstract}
Breast cancer is a heterogeneous disease, and the complexity of breast carcinogenesis is associated with epigenetic modification. There are several major classes of epigenetic enzymes that regulate chromatin activity. This review will focus on the nine mammalian protein arginine methyltransferases (PRMTs) and the dysregulation of PRMT expression and function in breast cancer. This class of enzymes catalyse the mono- and (symmetric and asymmetric) di-methylation of arginine residues on histone and non-histone target proteins. PRMT signalling (and R methylation) drives cellular proliferation, cell invasion and metastasis, targeting (i) nuclear hormone receptor signalling, (ii) tumour suppressors, (iii) TGF- $\beta$ and EMT signalling and (iv) alternative splicing and DNA/chromatin stability, influencing the clinical and survival outcomes in breast cancer. Emerging reports suggest that PRMTs are also implicated in the development of drug/endocrine resistance providing another prospective avenue for the treatment of hormone resistance and associated metastasis. The complexity of PRMT signalling is further underscored by the degree of alternative splicing and the scope of variant isoforms (with distinct properties) within each PRMT family member. The evolution of PRMT inhibitors, and the ongoing clinical trials of PRMT inhibitors against a subgroup of solid cancers, coupled to the track record of lysine methyltransferases inhibitors in phase I/II clinical trials against cancer underscores the potential therapeutic utility of targeting PRMT epigenetic enzymes to improve survival outcomes in aggressive and metastatic breast cancer.
\end{abstract}

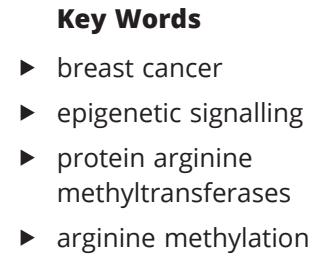

Journal of Molecular Endocrinology (2019) 62, R223-R237

\section{Introduction}

The frequency of breast cancer is escalating with improved life expectancy and the increased adoption of western lifestyles (Jemal et al. 2011, Ferlay et al. 2015, Torre et al. 2015). Breast cancer is one of the most widespread invasive cancers, which accounts for $25-30 \%$ of new cancers in women (AIHW 2012). It is responsible for $\sim 15 \%$ of cancerrelated mortality in females and accounts for $\sim 6.5 \%$ of all cancer-related deaths (OECD 2011, AIHW 2012).

Breast cancer is classified into carcinoma in situ, including ductal and lobular and invasive breast cancer
(IBC), including invasive/infiltrating ductal and invasive lobular (Lakhani 2012). Hormone-dependent breast cancer has been recognised and understood from the nineteenth century after Beatson performed the first oophorectomy in a woman with advanced metastatic breast cancer in 1895 (Love \& Philips 2002). However, the first description of breast cancer was documented as early as $1600 \mathrm{BC}$, and surgical tumour removal/breast cancer surgery began in the eighteenth century and was documented as early as the second century AD. 
Steroid hormones like oestrogen and progesterone play important roles in the growth and differentiation of the mammary gland and play a major role in the proliferation of neoplastic breast epithelium (Knight et al. 1977, Hankinson et al. 1998, Cauley et al. 1999, Russo \& Russo 2006). There is significant clinical and epidemiological evidence that associates prolonged exposure to oestrogens with increased risk of developing breast cancer (Knight et al. 1977, Hankinson et al. 1998, Cauley et al. 1999, Russo \& Russo 2006). With the discovery of the oestrogen receptor $\alpha(\mathrm{ER} \alpha)$ as a positive predictor of response to endocrine therapy, histological analysis and stratification of breast cancer tumours has been underpinned primarily by measuring the expression of two steroid hormone/nuclear hormone receptors (NRs), $\mathrm{ER}$ and the progesterone receptor (PR). In addition to ER/PR status, human epidermal growth factor receptor 2 (HER2) is utilised as an additional biomarker of disease diagnosis and avenue for therapeutic treatment (Arteaga et al. 2011). This practice (coupled to age, tumour type and size) remains common and serves to highlight current patient diagnosis, treatment and management (Oh et al. 2017) involving hormonal therapy, radiation and/or chemotherapy. For example, the ER/hormonedependent therapies, tamoxifen, fulvestrant and letrozole are used to selectively inhibit, degrade ER and suppress E2 synthesis/availability, respectively, for the treatment of ER+ breast cancer, underscoring the therapeutic utility of NRs in human health (Oh et al. 2017). In addition, the HER2-targeted therapy, utilising a monoclonal antibody (e.g. trastuzumab) that targets the epidermal growth factor receptor (a tyrosine kinase receptor) encoded by the $E R B B 2 / H E R 2$ gene, is utilised as an adjuvant treatment for HER2+ (ER+ and ER-) patients displaying HER2 protein over-expression or HER2 gene amplification). ER+, HER2+ and triple-negative breast cancers (TNBC; ER-/PR-/HER2-) account for $~ 70, \sim 15-20$ and $~ 10-15 \%$, respectively, of IBC (Cuzick et al. 2010, Arteaga et al. 2011, Oh et al. 2017).

Unfortunately, breast cancer is a very diverse and heterogeneous disease, it is accepted that these timehonoured conventional approaches are imperfect in their capacity to unfailingly identify and stratify breast cancer subtypes. This observation and challenge has promoted a comprehensive molecular footprinting of breast cancer subtypes to enhance and complement the historic approaches (Cancer Genome Atlas Network 2012) in the drive to improve therapeutic strategies and survival outcomes. Exhaustive and meticulous profiling studies of IBCs in a landmark study by Perou et al. (2000) provided the foundation for further studies (Perou et al. 2000), which identified several tumour subtypes, including luminal A and B, HER2+, basal-like (A and B) triple-negative tumours and the unclassified normal/ breast-like group ER positive/HER2 negative (very similar to luminal A, reviewed in Masood 2016). The subtype discrimination utilised $\sim 500$ genes that differentiated the subgroups based on gene expression footprints. The luminal A and B are ER+, HER2-negative subtypes that express ER (and/or PR) and GATA3 (and associated downstream regulated genes). Luminal $\mathrm{A}$ and $\mathrm{B}$ breast cancer are associated with low and high Ki-67 expression (that drives cellular proliferation) indicating better and poorer prognosis and survival outcomes, respectively. The HER2-enriched (HER2+) tumours are generally ER and PR negative and have a poor prognosis; however, targeted therapies are often associated with successful outcomes. The basal-like A and B tumours display no (or very low) HER2, ER and PR expression, with elevated expression of basal epithelial genes (including cytokeratin and integrin B4) and are often associated with BRCA1 gene mutations and elevated Ki-67 expression. The basal-like tumours are aggressive and metastatic, with poor clinical and survival outcomes. Advanced analysis and subsequent fine-tuning identified a total of 20 molecular subtypes displaying unique molecular, histological and pathologic profiles, underscoring the complexity of this disease. For example, this diverse and heterogeneous disease may also be partitioned into the following classifications: (i) Claudin-low (defined by elevated expression of epithelialmesenchymal, mammary stem cell biomarkers and immune response genes), (ii) molecular apocrine subtype (ER-/AR+ and includes the TNBC and HER2+ subtypes) and (iii) a novel luminal-like subtype (ER-/HER2-) (reviewed in Tang \& Tse 2016).

Regrettably, despite disease heterogeneity, present day patient treatment and management, largely remains restrained by the histological evaluation and status of the three major markers (ER/PR/HER2 status). Nextgeneration sequencing and cell biological and precision medicine approaches to finely map subtypes have not yet become a common clinical practice and/or utilised (with the exception of several cancer centres using precision medicine). Unfortunately, despite the success and efficacy of hormone-dependent therapies targeting ER $\alpha$ action as discussed earlier, resistance to endocrine therapies occurs in many patients with aggressive ER+ subtypes. Moreover, these cancer subtypes are associated with relapse/recurrence and/or metastasis linked to persistent ER $\alpha$ expression and E2-independent activity. Several 
ligand-independent functions of ER $\alpha$ signalling underlying the clinical development of endocrine resistance have been reported: (i) constitutive coactivator recruitment involving CARM1, (ii) NCOA3, (iii) RUNX2-ER-dependent SOX9 expression and (iv) pro-inflammatory cytokine-mediated activation of ER $\alpha$ (Louie et al. 2004, Carascossa et al. 2010, Jeselsohn et al. 2017, Stender et al. 2017). Moreover, TNBCs (ER-/PR-/HER2-) and other subtypes (e.g. basal) are unresponsive to hormonal treatments, respond poorly to chemotherapy and are associated with metastasis. In addition, current treatments are associated with side effects, inefficient utility against the diversity of subtypes and the development of endocrine resistance, underscoring (i) the need to identify new biomarkers, mechanisms and causes of breast cancer and (ii) the urgency to identify novel pharmaceuticals (Oh et al. 2017) and adjuvant treatments with utility against many molecular and metastatic subtype (Cuzick et al. 2010, Arteaga et al. 2011, Muscat et al. 2013, Oosterwijk et al. 2014, Oh et al. 2017).

Drugs targeting dysfunctional (hormone-dependent) NR signalling, for example, the FDA-approved hormonedependent therapies targeting E2/ER $\alpha$ signalling, display utility against breast cancer, but with the limitations mentioned. Interestingly, genetic alterations do not provide a complete appreciation of breast cancer. Currently, $>80 \%$ of neoplastic breast cancer occurs in women with no preceding substantiation of family history, that is, defined genetic mutations (Oosterwijk et al. 2014). However, hormone-dependent transcriptional control by ligandbound NRs involves the recruitment of coactivators, corepressors and epigenetic enzymes that function to amplify (and modulate) transcriptional regulation (Lonard \& O'Malley 2012). This provides additional windows into mechanistic and medicinal targeting of pathways that control gene regulation. Emerging literature has identified a complex interplay among many other members of the NR signalling superfamily (in addition to ER and PR), coregulators and epigenetic enzymes, which play significant roles in non-familial breast cancer. This was highlighted in our studies that identified differential expression of the NR superfamily (Muscat et al. 2013) (that accounts for $\sim 15 \%$ of prescription pharmaceuticals and FDA approvals), coregulators and epigenetic enzymes including the protein arginine methyltransferases (PRMTs) in (ER+ and ER-) breast cancer relative to normal breast (Dowhan et al. 2012, Doan et al. 2014, Oh et al. 2014, 2016). The NR and co-regulator/epigenetic signatures displayed prognostic and therapeutic utility in predicting clinical outcomes (Dowhan et al. 2012, Doan et al. 2014, Oh et al. 2014, 2016).
Epigenetic activity chemically alters the chromatin (for example, modifications, including methylation and acetylation status of DNA, histones and transcriptional regulators) and brings about cell-, tissue- and organ-specific epigenetic phenotypes. Epigenetic control and regulation defines alterations in genome function that emerge without alterations in DNA sequence. Aberrant epigenetic alterations drive human disease and are piloted by many enzymes including the lysine methyltransferases (KMTs), lysine demethylases (KDMs), protein arginine methyltransferases (PRMTs), histone lysine acetyltransferases (HATs), histone lysine deacetylases (HDACs) and DNA methyltransferases (DNMTs), particularly in the context of cancer and breast carcinogenesis (Arrowsmith et al. 2012, Oh et al. 2017). These epigenetic enzymes control the epigenomic modifications that are notable drivers of transcriptional regulation, cancer (breast carcinogenesis), proliferation, immortalisation and invasion (Yang \& Bedford 2013, Poulard et al. 2016, Blanc \& Richard 2017, Oh et al. 2017). This review will focus on epigenetic modifications directed by protein arginine methyltransferases (PRMTs) enzymes that methylate arginine amino acids, have critical roles in NR signalling, breast carcinogenesis and silencing of tumour suppressors (Harrison et al. 2010, Teyssier et al. 2010) and are tractable drug targets in many varieties of cancer (Copeland et al. 2009, Richon et al. 2011, Hu et al. 2016, Oh et al. 2017, Copeland 2018).

Epigenetic drug development targeting PRMTs is focused on the reversibility of epigenomic modifications through targeted inhibition of PRMT enzymes. Fortunately, there are sufficient structural distinctions that tolerates and enables selective targeting of PRMTs (Richon et al. 2011) using small-molecule inhibitors, creating desirable targets for therapeutic exploitation (Kaniskan \& Jin 2017, Copeland 2018). Moreover, the potential translational outcomes associated with the tractable PRMT family are underscored by the list of epigenetic enzyme inhibitors undergoing appraisal in pre-clinical and clinical trials as novel cancer therapies (Hamamoto \& Nakamura 2016, Oh et al. 2017). In summary, promising studies highlight the tractable nature and therapeutic utility of epigenetic enzymes in drug discovery and cancer. This review will focus on the role of PRMTs in breast carcinogenesis. Moreover, it will highlight (i) the rapidly maturing functional role of the PRMT epigenetic enzymes that have an impact on disease relapse, clinical and survival outcomes in breast cancer (Oh et al. 2017) and (ii) the emerging potential to therapeutically exploit this class of druggable enzymes as adjuvant treatments to control disease recurrence, metastasis and clinical outcomes. 


\section{Overview of protein arginine methyltransferases}

Protein arginine methylation is a common posttranslational modification catalysed by an HMT family of nine mammalian protein arginine methyltransferases (PRMTs) (Fig. 1A) (Yang \& Bedford 2013, Blanc \& Richard 2017) that have critical roles in steroid/NR-dependent signalling and breast cancer (Harrison et al. 2010, Teyssier et al. 2010). The PRMTs are a class of enzymes that transfer a methyl group from SAM to the guanidino nitrogen of arginine residues. PRMTs generate three types of arginine methylation modifications: (i) monomethylarginine (MMA), (ii) asymmetric dimethylarginine (ADMA) and (iii) symmetric dimethylarginine (SDMA) (reviewed in Poulard et al. 2016) and S-adenosylhomocycteine (Fig. 1B). MMA is produced in the initial reaction, followed by a sequential catalytic reaction that drives further turnover and methylation resulting in dimethylarginines (Fig. 1B). Arginine residue methylation modifies the structure and hydrogen bonding, altering DNA/RNA-protein and

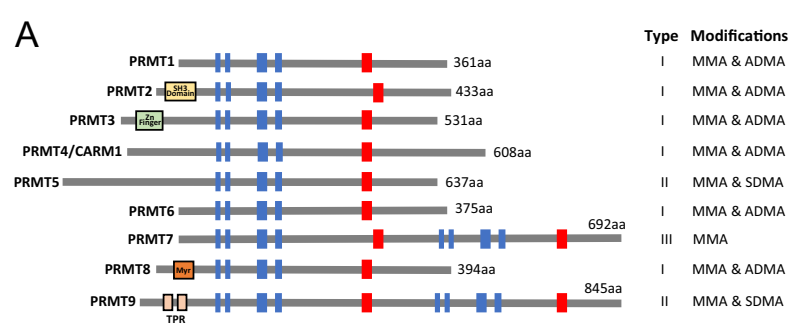

B

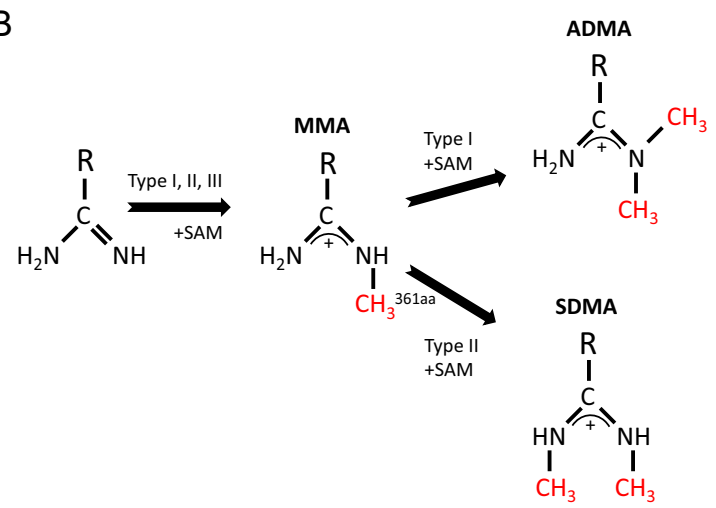

\section{Figure 1}

(A) Schematic representations of mammalian PRMT1-9. All members consist of conserved signature motifs I, post I, II and III, in blue bar respectively, and the THW loop (red). PRMT7 and PRMT9 contains two sets of catalytic conserved domains. Other motifs: SH3, SH3 domain; $\mathrm{Zn}$ Finger, Zinc Finger domain; Myr, myristoylation motif; TPR,

tetratricopeptide repeats. (B) Methylation on arginine residues (R) by methyltransferases PRMTs involves a two-step reaction. In the first step, monomethylarginine (MMA) is generated by type I, II and III PRMTs, followed by asymmetrical demethylation (ADMA) by type I and symmetrical demethylation (SDMA) by type II. protein-protein interactions, modulating biological responses (reviewed in Morales et al. 2016).

Human PRMTs can be can be classified into three catalytic groups: type I includes PRMT1, PRMT2, PRMT3, CARM1/PRMT4, PRMT6 and PRMT8; type II PRMT5 and PRMT9 and type III PRMT7 (Figs 1 and 2). The PRMT family is established around a highly conserved catalytic core (signature methyltransferase motifs (post I, II and III) and a $\beta$-barrel like domain that promotes substrate binding). In contrast, the amino (N)- and carboxyl (C)-terminal regions are highly divergent, indicating that PRMTs have unique specificities to different substrates (Fig. 1A) (reviewed and discussed in Morales et al. 2016). Types I and II produce ADMA and SDMA (Fig. 1B), respectively, targeting histone and non-histone proteins. In contrast, the type III enzyme, PRMT7 drives the establishment of monomethylarginine (MMA) and specifically modifies histone arginine residues and automethylation (reviewed in Schapira and Ferreira de Freitas 2014, Boriack-Sjodin and Swinger 2016, Morales et al. 2016) (Fig. 2).

The PRMT enzymes dynamically regulate chromatin structure and function as coregulators, that coactivate and co-repress transcription and gene expression (Yang \& Bedford 2013, Blanc \& Richard 2017). Blanc and Richard (2017) state 'PRMTs deposit key activating (histone H4R3me2a, H3R2me2s, H3R17me2a, H3R26me2a) or repressive (H3R2me2a, H3R8me2a, H3R8me2s, H4R3me2s) histone marks' (Fig. 2). For example, PRMT5 modulates methylation of $\mathrm{H} 2, \mathrm{H} 3$ and $\mathrm{H} 4$, which suppresses the expression of tumour suppressor genes (Peng \& Wong 2017). PRMTs influence a diverse range of cellular processes (summarised in Fig. 2) including growth, proliferation, differentiation, transcription, DNA damage and repair, immune system, RNA processing/alternative splicing and signal transduction (Yang \& Bedford 2013, Poulard et al. 2016, Blanc \& Richard 2017, Peng \& Wong 2017).

Furthermore, an increasing body of literature highlights the expression of PRMTs is associated with carcinogenesis, tumour progression and metastasis of breast cancer (Morettin et al. 2015). The complexity of PRMT function and the biological role of epigenetic enzyme-mediated protein methylation in the regulation of cellular proliferation and tumourigenesis (recently reviewed in Raposo \& Piller 2018) is further underscored by the extent of RNA processing/alternative splicing associated with the formation of the PRMT1, 2 4, 5, 7 and 9 variant splice forms with specific functions (Cook et al. 2006, Sohail \& Xie 2015) and reviewed in Baldwin et al. (2014). 


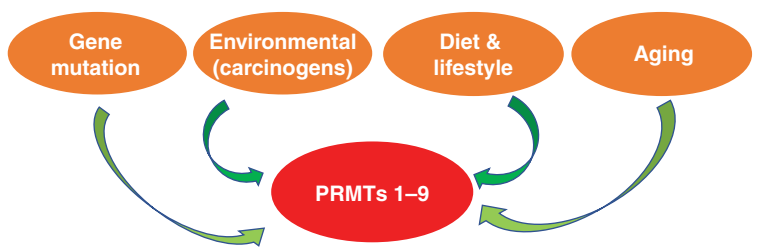

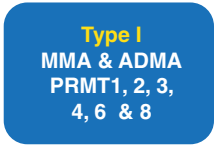

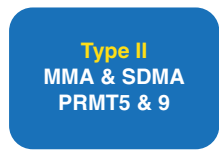

$\square$

Alternatively spliced variant isoforms exist for each PRMT family member.
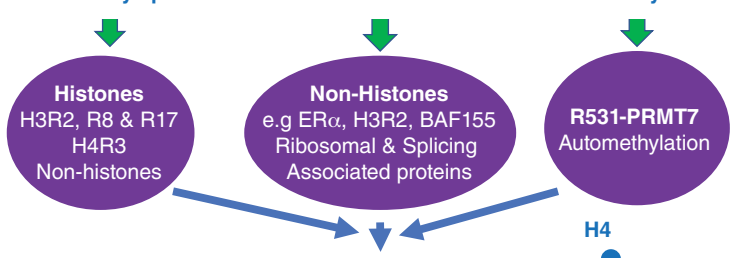

H4
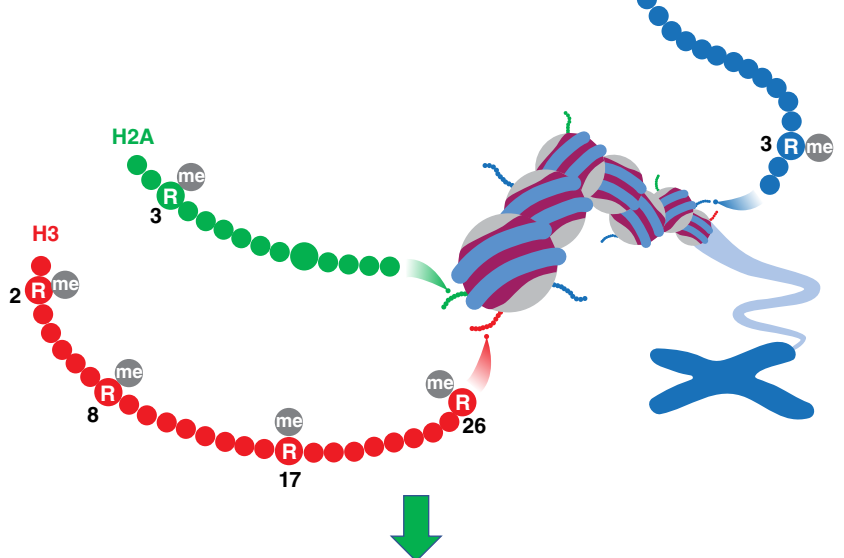

Functions in breast cancer

\begin{tabular}{|c|c|c|c|c|c|}
\hline $\begin{array}{c}\text { Transcription, } \\
\text { Alternative } \\
\text { Splicing } \\
\text { \& Gene } \\
\text { Regulation }\end{array}$ & $\begin{array}{l}\text { Reduced } \\
\text { Tumour } \\
\text { Suppressor } \\
\text { Expression/ } \\
\text { activity }\end{array}$ & $\begin{array}{l}\text { Attenuated } \\
\text { DNA repair } \\
\& \\
\text { Genome } \\
\text { stability }\end{array}$ & $\begin{array}{l}\text { Cellular } \\
\text { Proliferation } \\
\text { \& Growth }\end{array}$ & $\begin{array}{c}\text { Cell invasion, } \\
\text { TGF- } \beta \text { \& } \\
\text { EMT } \\
\text { signalling }\end{array}$ & $\begin{array}{c}\text { Disease } \\
\text { Recurrence, } \\
\text { reduced } \\
\text { survival \& } \\
\text { Endocrine } \\
\text { resistance }\end{array}$ \\
\hline
\end{tabular}

\section{Figure 2}

Schematic describing protein arginine methyltransferase epigenetic signalling and the post-translational epigenetic arginine methylation marks driven by PRMTs 1-9, which regulate gene expression and critical cancer pathways in breast carcinogenesis.

Aberrant PRMT expression has been linked to the pathogenesis of a number of human diseases, including many different types of cancer (Cuzick et al. 2010, Arteaga et al. 2011, Yang \& Bedford 2013, Poulard et al. 2016, Blanc \& Richard 2017, Oh et al. 2017), neurodegenerative diseases and metabolic disorders. In the context of risk factors impacting on cancer it should be mentioned that age, diet and lifestyle factors effect PRMT expression and activity. For example, PRMT expression and activity have been shown to be age dependent and display distinct organ-specific spatio-temporal patterns of expression (Hong et al. 2012). However, increased PRMT activity, R methylation (ADMA) and plasma/tissue levels of ADMA are associated with obesity, type 2 diabetes, fatty liver and cardiovascular disease (Matsuguma et al. 2006, Gruber et al. 2008, Maas et al. 2009, Abhary et al. 2010, Lee et al. 2011, Bouras et al. 2013, Rochette et al. 2013). In addition, in the context of dietary factors, increased blood glucose (hyperglycaemia) leads to aberrant methylation of proteins. Haploinsufficiency of PRMTs, PRMT depletion and overexpression have been associated with improved and aberrant glycaemic control, respectively (Choi et al. 2012, Han et al. 2014). Moreover, red wine consumption has been associated with decreased PRMT activity and ADMA expression (Scalera et al. 2009), and lifestyle and cardiovascular risk factors are negatively correlated with enzymes catalysing ADMA metabolism (Puchau et al. 2009).

The role of PRMT action in breast carcinogenesis and survival outcomes is poorly understood. Here, we provide a review focused on the biological roles and clinical relevance of these PRMTs in breast cancer, disease relapse and clinical outcomes. PRMT function reveals a new interface for potential therapeutic exploitation of novel adjuvant pharmacological targets. PRMTs have been demonstrated to control transcription/gene expression by functioning, in part, as coregulators for a range of transcription factors, including nuclear receptor that mediate hormone-dependent gene regulation (Bedford $\&$ Clarke 2009). Initial studies have identified differential expression of several PRMT proteins as having a key role in breast cancer, prostate cancer, gastric cancer, lymphoma and leukaemia (Poulard et al. 2016). Moreover, hazard and survival analysis demonstrated elevated expression of the PRMTs was associated with adverse clinical outcomes in breast cancer (Oh et al. 2017).

\section{Protein arginine methyltransferase in breast carcinogenesis and clinical outcomes}

\section{Protein arginine methyltransferase 1}

PRMT1 belongs to the type I class of enzymes, accounts for $(>90 \%)$ arginine methylation and modulates gene expression in a variety of cell types (Tang et al. 2000). Gao et al. (2016) showed that PRMT1 is recruited to the of ZEB1 promoter region and mediates H4R3me2a methylation that induces and directs the epithelialmesenchymal transition (EMT) process (Gao et al. 2016). 
The histone 4 arginine 3 residue (H4R3me2a) targeted by PRMT1 has been implicated in transcriptional activation and inducing tumourigenic pathways (Shia et al. 2012).

In addition, it has been reported PRMT1 directly methylates non-histone proteins, for example, PRMT1 methylates the arginine residue 260 (R260) in the DNAbinding domain of ER $\alpha$ in vitro and in vivo, underscoring the significant role of PRMT1 in breast cancer (Le Romancer et al. 2008).

Alternative splicing of PRMT1 is associated with isoform-specific substrate specificity and unique nucleocytoplasmic patterns of expression. The expression of the PRMT1v2 alternatively spliced isoform variant is significantly elevated in breast cancer, and expression is primarily localised in the cytoplasm. PRMT1v2 gain- and loss-of-function analysis in breast cancer cells increased and reduced cell invasion, respectively, and is dependent on its distinct N-terminal that affects PRMT1 catalytic activity and substrate specificity (Baldwin et al. 2012). Survival analysis in breast cancer cohorts suggested that low PRMT1v1 expression was associated with the better probability of disease-free survival (DFS; $P=0.036$ ) (Mathioudaki et al. 2011) and in accord with observations that PRMT1-dependent methylation regulates several critical cellular processes in tumourigenesis. These and previous studies implied that elevated PRMT1 expression is potentially associated with poor survival in breast cancer. In agreement, it has been demonstrated that PRMT1 expression was associated with poor prognosis and survival, using $>3500$ breast cancer patients from the kmplot datasets (Gyorffy et al. 2010, Oh et al. 2017).

\section{Protein arginine methyltransferase 2}

The expression of PRMT2 is significantly increased in breast cancer (Zhong et al. 2012) and Qi et al. (2002) demonstrated PRMT2 coactivates ER $\alpha$. In addition, Meyer et al. (2007) also reported PRMT2 interacts with the NRs ER $\alpha$ and ER $\beta$, implying this co-regulator has a notable role in breast carcinogenesis (Qi et al. 2002, Meyer et al. 2007). PRMT2 depletion studies in mouse embryonic fibroblast (MEF) cells induced E2F activity and cell cycle progression, providing evidence for its role in cellular proliferation (Yoshimoto et al. 2006). Zhong et al. (2011) demonstrated that PRMT2 and its alternately spliced transcripts are positively associated with ER $\alpha$ status and breast cancer, and preferentially expressed in oestrogen/ER $\alpha$ target cells and tissues (Zhong et al. 2011). They further reported that several PRMT2 splice variants interact with ER $\alpha$ and coactivate ER $\alpha$-dependent gene expression including trans-activation of critical ER $\alpha$ target genes. This implied elevated PRMT2 expression is potentially linked with breast cancer.

Zhong et al. (2014) further demonstrated that PRMT2 attenuates breast cancer cell growth; moreover, they showed that PRMT2 decreased cyclinD1 expression by mechanism dependent on inhibition of ER $\alpha$ recruitment to the AP1 cognate-binding site in the cyclinD1 promoter. Interestingly, the group reported that nuclear loss of PMRT2 positively correlated with the grade of ductal carcinoma and cyclinD1 expression (Zhong et al. 2014). Oh et al. (2014) exploited PRMT2 loss-of-function studies in MCF-7 cells and observed that PRMT2-dependent gene expression was involved in cell cycle regulation, checkpoint control, chromosomal instability and DNA repair (Oh et al. 2014). Further biochemical and DNA repair analysis demonstrated PRMT2 knockdown induces nucleotide excision repair of UV-induced DNA lesions and promotes homologous recombination repair of doublestranded breaks. WGCNA analysis identified a significant association between PRMT2-dependent gene expression, checkpoint control and DNA repair, which correlated with the pan-cancer metagene signatures that drive epithelialmesenchymal transitions and chromosomal instability in human cancer cohorts (Oh et al. 2014). Furthermore, elevated expression of the PRMT2 gene signature is significantly associated with decreased probability of distance metastasis-free survival (DMFS). Additional analysis revealed (i) a negative correlation between the expression of PRMT2 and the NR, ROR $\gamma$ in ER+ breast cancer and (ii) increased $\mathrm{ROR} \gamma$ expression is associated with increased survival (Oh et al. 2016). Hazard ratio analysis (with Cox regression) in several human breast cancer cohorts accordingly supported these observations demonstrating that higher PRMT2 expression decreases the probability of DMFS in breast cancer patients (Oh et al. 2014, 2017) and is associated with poorer clinical outcomes. In contrast, increased $R O R \gamma$ expression improves the probability of DMFS. Concordance index analysis (a means of quantifying discriminatory power of prediction) established that the PRMT2 signature very efficiently predicts breast cancer risk (Oh et al. 2014).

Zhong et al. (2017) observed that overexpression of the PRMT2 $\beta$ splice variant (that harbours a novel C-terminal region) in MCF-7 breast cancer drives cell cycle withdrawal, decreased cell growth and colony formation. The mechanism involved attenuation of the cyclinD1 promoter activity. Furthermore, PRMT2 $\beta$ expression was inversely correlated with human epidermal growth factor 2 (HER2) expression in breast tumours (Zhong et al. 2017). 
Oestrogen and ER $\alpha$ are important drivers of hormonedependent breast cancer. There are two splice variants of $\mathrm{ER} \alpha, \mathrm{ER} \alpha 66$ and ER $\alpha 46$. ER-positive (hormone-dependent) breast cancer is associated with overexpression of the ERo66 splice variant. It has been demonstrated that tamoxifen treatment reduces PRMT2 expression and induces the expression of ER $\alpha 36$. Moreover, PRMT2 also interacts with ER $\alpha 36$ (Shen et al. 2018). Curiously, in TNBC MDA-MB-231 cells, PRMT2 expression increased the sensitivity to tamoxifen and attenuated ER $\alpha 36$ expression; however, no significant association between PRMT2 and ERa36 expression could be identified in breast cancer cohorts (Shen et al. 2018). In summary, the reports to date in the literature underscore the role of PRMT2 in cell cycle control, DNA repair and genome stability; further studies are required to address some apparent contradiction on the effect of PRMT2 expression on cell cycle control in breast cancer cells, the regulation of cyclinD1 expression and differential expression in breast cancer patients. It is plausible these discrepancies are associated with variant isoform expression (and the range of alternatively processed PRMT2 transcripts), the sub-cellular localisation of these epigenetic enzymes that shuttle between the nucleus and cytoplasm and patient cohorts. Hazard and survival analysis in a number of human breast cancer patient cohorts clearly indicates elevated expression of PRMT2 (and the PRMT2-dependent gene signature) is associated with poorer clinical and survival outcomes.

\section{Protein arginine methyltransferase 3}

The function of PRMT3 in breast cancer and carcinogenesis remains obscure. PRMT3 expression has been reported to be associated with poor survival and high hazard ratio score indicating PRMT3 targeting and inhibition may provide therapeutic options for breast carcinogenesis (Oh et al. 2017). In the context of PRMT function and the expression of tumour suppressors, DAL-1 (differentially expressed in adenocarcinoma of the lung)/4.1B tumour suppressor has been demonstrated to interact with PRMT3, resulting in the attenuation of PRMT3-mediated methylation in breast cancer cells (Singh et al. 2004), and the induction of apoptosis of breast cancer cells (Jiang \& Newsham 2006). Swiercz et al. (2005) reported the ribosomal protein S2 is methylated by and interacts with PRMT3 suggesting it has a role in regulating protein synthesis (Swiercz et al. 2005). In accord, PRMT3 deficient mouse model was found to be associated with hypomethylated ribosomal protein S2 (Swiercz et al. 2007). Another report demonstrated that the von Hippel-Lindau tumour suppressor that attenuates carcinogenesis and angiogenesis interacts with PRMT3 and the associated protein complex to asymmetrically dimethylate $\mathrm{R}$ residues in the major tumour suppressor, p53 (Lai et al. 2011). In summary, the studies to date suggest that PRMT3 is involved in controlling protein synthesis and modulating tumour suppressor function in breast cancer.

\section{Protein arginine methyltransferase 4}

PRMT4 also denoted as coactivator-associated arginine methyltransferase 1 (CARM1 in humans) was identified as a transcriptional co-regulator (Chen et al. 1999) and has been reported as an ERo co-regulator (Al-Dhaheri et al. 2011). CARM1 positively correlates with ER $\alpha$ in the ER+ subtype, but is negatively correlated with histological grade and is reported as an improved biomarker of breast cancer cell differentiation (Al-Dhaheri et al. 2011). Davis et al. (2013) observed that the sub-cellular localisation of this ER $\alpha$ co-regulator is differentially associated with breast cancer subtypes. For example, elevated nuclear expression of CARM1 was observed in the HER2 subtype (Davis et al. 2013). Moreover, cytoplasmic expression of CARM1 links with specific breast cancer subtypes, and increased cytoplasmic expression of CARM1 is linked with the ER- subtypes. Finally, a higher cytoplasmic/ nuclear ratio is associated with African patient subgroups, and the authors suggested that subtype-specific cellular localisation maybe associated with specific subtype aetiology (Davis et al. 2013). Cheng et al. (2013) reported that increased expression of CARM1 was associated with high Ki-67 index and HER2 expression in the HER2, luminal B and TNBC IBC subtypes (Cheng et al. 2013). This report also supported the prognostic analysis of breast cancer subtypes by CARM1 expression; however, the study did not provide insights into cytoplasmic vs. nuclear staining (Cheng et al. 2013). In this context, Habashy et al. (2013) reported that CARM1 expression was significantly associated with the expression of HER2, p53, Ki-67 and other proliferative markers. Inverse links with luminal biomarkers associated with less aggressive breast cancer subtypes were identified (Habashy et al. 2013). Oh et al. (2017) interrogated several breast cancer datasets and confirmed that increased CARM1 expression is significantly associated with adverse clinical and survival outcomes (Oh et al. 2017). Two alternately spliced isoforms of CARM1 has been reported, the full-length and truncated forms, denoted as CARM1FL and CARM1 $\Delta \mathrm{E} 15$, respectively. Curiously, despite the full-length and the truncated form displaying preferential sub-cellular 
localisation in the nucleus and cytoplasm, respectively, no association between the expression of these isoforms with breast cancer, subtype and or tumour volume could be identified in patient cohorts (Shlensky et al. 2015).

CARM1 was demonstrated to methylate the chromatin remodelling SWI/SNF core subunit, BAF155. The methylation of the arginine 1064 residue of BAF155 displayed significant prognostic utility in the context of breast cancer recurrence and metastasis (Wang et al. 2014). The report demonstrated that CARM1-dependent arginine methylation of BAF155 drives carcinogenic activity associated with migration and metastasis. This is in accordance with results by Sharma et al. (2017) who identified the gene network modules including CARM1 and ER signalling modules associated with metastasis and the progression of the disease (Sharma et al. 2017). Furthermore, JmjC domain containing protein 6 (JMJD6) drives the interaction with the MED12 mediator complex that interacts with CARM1 and is involved in ER $\alpha$ dependent breast cancer cellular proliferation (Gao et al. 2018). Hiken et al. (2017) demonstrated that aromatise inhibitor endocrine-resistant breast cancer is associated with increased prostaglandin $\mathrm{E}_{2}$ receptor 4 (PTGER4) expression, a protein that drives agonist-independent activity of CARM1 (Hiken et al. 2017).

Sack et al. (2011) demonstrated CARM1 inhibition via indole and pyrazole-derived structures (Sack et al. 2011). This created opportunities for the pharmacological manipulation of this epigenetic enzyme as a therapeutic tool against breast cancer. Summarising, CARM1/PRMT4 demonstrates prognostic utility as a biomarker, with subtype-specific insights and functions; however, there is variance and disagreement in the literature with respect to its correlation with the grade of tumour that may reflect its breast cancer subtype-specific expression and sub-cellular localisation. It's clear role as an ER $\alpha$ co-regulator in breast cancer cells highlights its significant role in breast cancer, and the consensus to date is that CARM1 expression is associated with poorer clinical outcomes.

\section{Protein arginine methyltransferase 5}

PRMT5 belongs to the type II class of arginine methyltransferases that produce SDMA modifications on the appropriate arginine residues. There is an increasing number of reports on the carcinogenic function of PRMT5 in breast cancer, and its attenuation of tumour suppressor activity. For example, Powers et al. (2011) observed PRMT5 is co-expressed with tumour suppressor programmed cell death 4 (PDCD4), which is often associated with improved clinical outcomes in several cancers. In breast cancer, co-expression of these markers is associated with poorer outcomes and correlates with PRMT5dependent methylation of PDCD4 (Powers et al. 2011). Overexpression and association of PRMT5 and tumour necrosis factor receptor-associated 4 (TRAF4) was found in breast cancer, with (nuclear) PRMT5 expression. TRAF4 interacts with PRMT5 and drives cellular proliferation (Yang et al. 2015a).

Li et al. (2015) identified the tumorigenic role of PRMT5 in lymphomagenesis and potentiated the increased expression of oncogenic drivers ( $\mathrm{Li}$ et al. 2015). PRMT5 was demonstrated to drive arginine (R) methylation of the cell fate regulator, KLF4 (inhibiting ubiquitylation and turnover) and associated with increased expression of p21 (Hu et al. 2015). In contrast, genotoxic stress (effecting genome stability) attenuates the PRMT5-dependent R methylation of KLF4, resulting in reduced KLF4 accumulation and cell cycle activation driving breast tumourigenesis (Hu et al. 2015). Chen et al. (2017) reported PRMT5 interacted with WDR77, the formation of the complex was associated with increased $\mathrm{R}$ methylation in cancer, and linked to poorer clinical outcomes (Chen et al. 2017). In concordance, PRMT5 expression was demonstrated to be correlated with poor prognosis and clinical outcomes (Oh et al. 2017). The PRMT5-WDR 77 activity is necessary for TGF- $\beta$ dependent EMT and metastatic processes that are associated with (i) PRMT-dependent R2 methylation and (ii) regulation of critical genes linked with TGF-beta-dependent cancer cell invasion pathways (Chen et al. 2017). Chiang et al. (2017) reported PRMT5 recruitment to the FOXP1 promoter drives breast cancer stem cell (BCSC) proliferation facilitated by H3R2 dimethylation and H3K4 trimethylation (Chiang et al. 2017). They further discussed the implications of inhibiting PRMT5 on BCSC stem cells and potential for decreasing rates of tumour relapse (Chiang \& Davies 2018). Consistent with these reports and considerations, PRMT5 inhibitor treatment decreases BCSC proliferation. Moreover, PRMT5 has also been demonstrated to modulate drug/chemotherapeutical sensitivity in BCSC cells (Wang et al. 2018). The complexity associated with the additional layer of alternate splicing of PRMTs cannot be ignored. For example, a shorter PRMT5 splice variant targets histone H4R3 methylation similar to the longer PRMT5 isoform; however, there is a different pattern of sub-cellular localisation and distinct targeting of genes associated with cellular proliferation (Sohail \& Xie 2015). In conclusion, PRMT5 expression is associated with poorer clinical outcomes, targets genes involved in cell 
fate determination and BCSC proliferation, and regulates gene expression associated with the induction of TGF- $\beta$ dependent cell invasion.

\section{Protein arginine methyltransferase 6}

Increasing evidence has suggested that PRMT6 expression also promotes and drives breast carcinogenesis. Harrison et al. (2010) reported PRMT6 co-activated oestrogen and progesterone receptor-dependent gene expression (including critical target genes) in association with the steroid receptor coactivator-1. Moreover, this study also demonstrated that enzymatic arginine methyltransferase activity of PRMT6 was necessary for the coregulation of the NRs (Harrison et al. 2010). In the context of breast cancer, PRMT6 regulates oestrogen-dependent breast cancer cell proliferation and alternative splicing of vascular endothelial growth factor and spleen tyrosine kinase. The increased expression of PRMT6 correlates with several cancer types, including breast, cervix, prostate and lung cancer, suggesting PRMT6 expression has a significant role in the onset/incidence and progression of cancer (Yoshimatsu et al. 2011). PRMT6 was also found to be necessary for cellular proliferation of breast cancer cells and are involved in the transcriptional attenuation of critical tumour suppressor genes (Stein et al. 2012). PRMT6 depletion was associated with increased expression of p21 and p16. Chromatin immunoprecipitation studies confirmed that PRMT6 is directly recruited by the $p 21$ gene (Stein et al. 2012). Furthermore, PRMT6 directly represses the p21 Waf1/Cip1 and p27 expression, binding on the promoter region (Kleinschmidt et al. 2012, Phalke et al. 2012), and further validated the effect of PRMT6 on cyclin-dependent kinase inhibitors. Neault et al. (2012) demonstrated that PRMT6 depleted mouse embryo fibroblasts were associated with cell cycle withdrawal, and increased expression of p21 and p53. The pathway involved the recruitment of PRMT6 to the p53 promoter and the methylation of H3R2 (Neault et al. 2012). In contrast, PRMT6 has been reported to operate as an oncogene directly attenuating the $p 21$ gene but in a p53independent manner in breast cancer cells (Phalke et al. 2012). In the context of cell growth, Nakakido et al. (2015) went onto demonstrate that PRMT6-dependent proliferation involved suppression of p21 by methylation at residue arginine 156 that mediated phosphorylation of threonine 145 on p21 and drives the sub-cellular localisation of p21 to the cytoplasm, increasing the resistance of cancer cells to antineoplastic agents (Nakakido et al. 2015).
Dowhan et al. (2012) identified and validated PRMT6dependent gene expression and alternate splicing in breast cancer cells and patient samples. This included (i) decreased expression of the tumour suppressor, PTEN in breast cancer patient samples and increased PTEN mRNA expression after PRMT6 depletion in breast cancer cells and (ii) differential splicing of genes involved in centrosome targeting, cell invasion, apoptosis, p21-interacting protein and other cell cycle regulators. Furthermore, they demonstrated that aberrant (and increased) expression of the PRMT6 and PRMT6-dependent gene signature is associated with poorer clinical outcomes in $\mathrm{ER}+$ breast cancer patients (i.e. increased probability of relapse/recurrence and metastasis) (Dowhan et al. 2012, Oh et al. 2017). Recently, Veland et al. (2017) provided evidence that PRMT6 suppresses DNA methylation, associated with methylation of $\mathrm{H} 3$ arginine 2 (H3R2), and increased PRMT6 expression plays a role in DNA hypomethylation in cancer. The mechanism involves the compromised recruitment of UHRF1 to chromatin, which is necessary for the activity of the DNA methyltransferase, DNMT1 (Veland et al. 2017). In summary, elevated PRMT6 is associated with increased recurrence and metastasis; moreover, PRMT6 signalling is associated with the attenuation of $\mathrm{p} 21$, increased proliferation and attenuation in the expression/activity of critical tumour suppressors. Shen et al. (2016) and Mitchell et al. (2015) reported that selective and specific PRMT4/6 and PRMT6 inhibitors, respectively, provide the platform to evaluate these small molecule pharmacological tools as potential anticancer compounds and utility of targeting PRMT4 and 6, respectively (Mitchell et al. 2015, Shen et al. 2016).

\section{Protein arginine methyltransferase 7}

The carcinogenic role of PRMT7 has been slowly evolving in the last decade. PRMT7 was originally classified as a type II class of PRMT, potentiating MMA and SDMA formation (Lee et al. 2005); however, a later investigation demonstrated PRMT7 activity drives the formation of mono-methylated arginine and is now classed as a type III PRMT enzyme (Zurita-Lopez et al. 2012). In the context of survival and clinical outcomes, Oh et al. (2017) provided evidence from the analysis of multiple cohorts that PRMT7 expression is linked with poor clinical outcomes and increased risk of relapse and metastasis (Oh et al. 2017).

Gene set enrichment analysis was utilised to identify PRMT7 as a differentially expressed causal gene for breast cancer metastasis (Thomassen et al. 2009). Yao et al. 
(2014) reported PRMT7 expression is increased in breast cancer and associated with the induction of epithelialmesenchymal transitions (Yao et al. 2014). The mechanism involved PRMT7 (and HDAC3) recruitment to the E cadherin promoter (suppressing $\mathrm{E}$ cadherin expression) and associated with increased H4R3 methylation and decreased lysine methylation during EMT activation. Depletion of PRMT7 reversed these effects on the E cadherin promoter and inhibited cell invasion in breast cancer cells (Yao et al. 2014). Moreover, PRMT7 drives the increased expression of the metastatic mediator, matrix metalloproteinase 9 (MMP9) and promotes invasion in breast cancer cells (Baldwin et al. 2015). These investigations highlighted the therapeutic potential of PRMT7 inhibition in breast carcinogenesis. Geng et al. (2017) reported that R531 of PRMT7 is automethylated and promotes the EMT process and mediates cell invasion. PRMT7 expression in MCF-7 cells in a nude mouse model drives the metastatic processes, whereas mutation of R531 attenuates the metastatic behaviour. PRMT7 automethylation (associated with the recruitment to the E cadherin promoter and E cadherin expression) is significantly associated with poor clinical outcomes (Geng et al. 2017). In summary, the studies to date suggest that PRMT7 is a (methylation-dependent) driver of cell invasion and metastasis mediated by the regulation of $\mathrm{E}$ cadherin.

\section{Protein arginine methyltransferase 8}

The function of PRMT8 in breast carcinogenesis requires further investigation. Oh et al. (2017) observed PRMT8 is associated with poor survival using z-score analysis of multiple breast cancer datasets; however, kmplot data and hazard ratio analysis indicated that PRMT8 expression was protective (Oh et al. 2017). Increased PRMT8 expression in breast cancer is associated with improved patient survival, and the novel PRMT8 isoform (variant2) was involved in cellular proliferation (Hernandez et al. 2017). Clearly, further analysis and studies are required to ascertain the role of PRMT8 in breast cancer survival and clinical outcomes and to elucidate the underlying mechanisms of action in the regulation of breast cancer proliferation.

\section{Protein arginine methyltransferase 9}

PRMT9 identified as a type II methyltransferase (Cook et al. 2006) similar to PRMT5, mediating the generation of MMA and SMDA. PRMT9 targets the spliceosome-associated protein (SAP) 145 at R508 and generates MMA and SDMA methylation marks on SAP145 (Yang et al. 2015b). The same study also identified PRMT6-dependent methylation of the R515 residue on SAP145. These methylation events were associated with significant changes in RNA splicing, and with the formation of binding sites that mediate the assembly of ribonucleoprotein complexes, necessary for snRNP development. The role of PRMT9 in breast cancer has not been investigated, however, Jiang et al. (2018) studied its role in hepatocellular carcinoma (HCC) and observed that PRMT9 overexpression drives HCC invasion and metastasis. PRMT9 expression was associated with increased rates of disease recurrence, and reduced survival, and a significant risk factor (for survival) after surgery (Jiang et al. 2018). PRMT9 overexpression promoted cellular migration, invasion and metastasis mediated by the EMT process and increased PI3K/Akt/GSK-3 $\beta /$ Snail signalling. In accord with those observations, PRMT9 depletion attenuated cell invasion. In HCC patient sample cohorts, PRMT9 expression significantly correlated with Snail expression (Jiang et al. 2018). In summary, the role of PRMT9 in breast cancer will be resolved in time but the similarities with other PMRT functions in the regulation of alternate splicing, cell invasion and metastasis underscores that the PRMTs display distinct and overlapping mechanism in the promotion of cell migration, invasion and metastasis during cancer.

\section{Emergence of PRMT inhibitors as therapeutic and clinical tools}

PRMT inhibitors were initially reported in 2004-2005, and recently selective, specific and potent PRMT inhibitors targeting PRMT3 (SGC707), CARM1 (PRMT4) (TP-064, MS049), PRMT5 and PRMT6 (EPZ020411) have been reported with membrane permeability and efficacy in cell culture and rodent models underscoring the therapeutic and pharmacological potential of targeting the PRMTs (recently reviewed in Kaniskan \& Jin 2017, Copeland 2018, Wu et al. 2018). PRMT5 inhibitors EPZ015938/GSK3326595 and JNJ-64619178 have been reported to (i) attenuate cancer growth in cell and animal models, (ii) display tumour inhibition and regression in a biomarker-driven xenograft model and extend tumour growth attenuation after termination of drug treatment and (iii) are currently in oral administration clinical trials (NCT02783300 and NCT03573310, respectively) to assess safety, tolerance, pharmokinetics and clinical utility against a subgroup of solid cancers and non-Hodgkin lymphoma and to determine the appropriate phase 2 dosing (reviewed in Kaniskan \& Jin 2017, Copeland 2018, 
Wu et al. 2018). These studies, the continual development of other PRMT inhibitors and the track record of lysine methyltransferase inhibitors in phase I/II clinical trials against solid tumours, leukaemia and lymphomas discussed in Copeland (2018) underscore the potential of pursuing PRMTs for the adjuvant treatment of breast cancer.

\section{Conclusion and future opportunities}

Breast cancer epigenetics is a rapidly evolving and emerging field of research that continues to develop our understanding of the pathophysiological and molecular mechanisms driving breast carcinogenesis. The tractability of this class of enzymes and modulators of gene regulation in the context of drug discovery, coupled to the rapid advances in next-generation sequencing technologies, is revealing new targets for adjuvant therapeutic control of breast cancer. The PRMT studies to date are divulging consensus genes/pathways targeted by PRMT signalling (Fig. 2). For example, PRMT signalling (and R methylation) drives cellular proliferation, cell invasion and metastasis, targeting: (i) ERo signalling, (ii) p21 and p53 and several other tumour suppressors, (iii) TGF- $\beta$ and EMT signalling and (iv) alternate splicing (Fig. 2). These downstream effects of PRMT signalling have an impact on clinical and survival outcomes. Existing literature and several preliminary reports at conferences suggest the PRMT that function as coregulators of ER $\alpha$ signalling are also involved in the development of drug/endocrine resistance providing another prospective avenue for the treatment of hormone resistance and associated metastasis. As discussed in the review, there has been some lack of accord in the analysis of the specific roles of several PRMTs in human breast cancer cell lines (for example, cell cycle regulation) and also some reported conflicts in disease relapse and survival analysis; however, the role and extent of alternative splicing, sub-cellular localisation and the scope of isoforms within each PRMT family member (associated with variant-specific functions) may account for several of these discrepancies (Cook et al. 2006; reviewed in Baldwin et al. 2014, Sohail \& Xie 2015). The next decade will certainly lead to the development and discovery of specific and selective PRMT inhibitors with utility against many cancers. The utility of these selective and specific compounds (for example, PRMT5 discussed above) coupled to the analysis of PRMT function in (i) mouse models of mammary tumourigenesis, (ii) breast cancer cell and (iii) patient-derived xenografts will resolve the distinct and overlapping functions/roles of these epigenetic enzymes in breast cancer.

Pharmacological exploitation of PRMT signalling and epigenetic activity presents the opportunity to improve clinical and survival outcomes that reduce the rates of tumour recurrence and metastasis. Therapeutic targeting of all the epigenetic enzyme classes in breast and many other cancers has the potential to provide novel and viable adjuvant treatment strategies for hormone resistant and metastatic breast cancer. Early clinical trials for PRMT5 and the Phase I/II track record for lysine methyltransferase inhibitors emphasise and draw attention to the vast promise and possibilities of pharmacologically attenuating this enzyme class in breast cancer.

\section{Declaration of interest}

The authors declare that there is no conflict of interest that could be perceived as prejudicing the impartiality of this review.

\section{Funding}

This research was supported by core institutional support from the Institute of Molecular Bioscience (IMB), The University of Queensland. GEOM (APP\#1059341) is National Health and Medical Research Council (of Australia) Principal Research Fellow.

\section{References}

Abhary S, Burdon KP, Kuot A, Javadiyan S, Whiting MJ, Kasmeridis N, Petrovsky N \& Craig JE 2010 Sequence variation in DDAH1 and DDAH2 genes is strongly and additively associated with serum ADMA concentrations in individuals with type 2 diabetes. PLOS ONE 5 e9462. (https://doi.org/10.1371/journal.pone.0009462)

Australian Institute of Health and Welfare \& Cancer Australia 2012 Breast Cancer in Australia: An Overview. Cancer series no. 71. Cat. no. CAN 67. Canberra, Australia: AIHW.

Al-Dhaheri M, Wu J, Skliris GP, Li J, Higashimato K, Wang Y, White KP, Lambert P, Zhu Y, Murphy L, et al. 2011 CARM1 is an important determinant of ERalpha-dependent breast cancer cell differentiation and proliferation in breast cancer cells. Cancer Research $\mathbf{7 1}$ 2118-2128. (https://doi.org/10.1158/0008-5472.CAN-10-2426) Arrowsmith CH, Bountra C, Fish PV, Lee K \& Schapira M 2012 Epigenetic protein families: a new frontier for drug discovery. Nature Reviews Drug Discovery 11 384-400. (https://doi.org/10.1038/ $\operatorname{nrd3674)}$

Arteaga CL, Sliwkowski MX, Osborne CK, Perez EA, Puglisi F \& Gianni L 2011 Treatment of HER2-positive breast cancer: current status and future perspectives. Nature Reviews Clinical Oncology 9 16-32. (https://doi.org/10.1038/nrclinonc.2011.177)

Baldwin RM, Morettin A, Paris G, Goulet I \& Cote J 2012 Alternatively spliced protein arginine methyltransferase 1 isoform PRMT1v2 promotes the survival and invasiveness of breast cancer cells. Cell Cycle 11 4597-4612. (https://doi.org/10.4161/cc.22871)

Baldwin RM, Morettin A \& Cote J 2014 Role of PRMTs in cancer: could minor isoforms be leaving a mark? World Journal of Biological Chemistry 5 115-129. (https://doi.org/10.4331/wjbc.v5.i2.115) 
Baldwin RM, Haghandish N, Daneshmand M, Amin S, Paris G, Falls TJ, Bell JC, Islam S \& Côté J 2015 Protein arginine methyltransferase 7 promotes breast cancer cell invasion through the induction of MMP9 expression. Oncotarget 6 3013-3032. (https://doi. org/10.18632/oncotarget.3072)

Bedford MT \& Clarke SG 2009 Protein arginine methylation in mammals: who, what, and why. Molecular Cell 33 1-13. (https://doi. org/10.1016/j.molcel.2008.12.013)

Blanc RS \& Richard S 2017 Arginine methylation: the coming of age. Molecular Cell 65 8-24. (https://doi.org/10.1016/j. molcel.2016.11.003)

Boriack-Sjodin PA \& Swinger KK 2016 Protein methyltransferases: a distinct, diverse, and dynamic family of enzymes. Biochemistry $\mathbf{5 5}$ 1557-1569. (https://doi.org/10.1021/acs.biochem.5b01129)

Bouras G, Deftereos S, Tousoulis D, Giannopoulos G, Chatzis G, Tsounis D, Cleman MW \& Stefanadis C 2013 Asymmetric dimethylarginine (ADMA): a promising biomarker for cardiovascular disease? Current Topics in Medicinal Chemistry 13 180-200. (https:// doi.org/10.2174/1568026611313020007)

Cancer Genome Atlas Network 2012 Comprehensive molecular portraits of human breast tumours. Nature 490 61-70.

Carascossa S, Dudek P, Cenni B, Briand PA \& picard D 2010 CARM1 mediates the ligand-independent and tamoxifen-resistant activation of the estrogen receptor alpha by cAMP. Genes and Development 24 708-719. (https://doi.org/10.1101/gad.568410)

Cauley JA, Lucas FL, Kuller LH, Stone K, Browner W \& Cummings SR 1999 Elevated serum estradiol and testosterone concentrations are associated with a high risk for breast cancer. Study of Osteoporotic Fractures Research Group. Annals of Internal Medicine 130 270-277. (https://doi.org/10.7326/0003-4819-130-4_Part_1-199902160-00004)

Chen D, Ma H, Hong H, Koh SS, Huang SM, Schurter BT, Aswad DW \& Stallcup MR 1999 Regulation of transcription by a protein methyltransferase. Science 284 2174-2177. (https://doi.org/10.1126/ science.284.5423.2174)

Chen H, Lorton B, Gupta V \& Shechter D 2017 A TGFbeta-PRMT5-MEP50 axis regulates cancer cell invasion through histone $\mathrm{H} 3$ and $\mathrm{H} 4$ arginine methylation coupled transcriptional activation and repression. Oncogene 36 373-386. (https://doi.org/10.1038/onc.2016.205)

Cheng H, Qin Y, Fan H, Su P, Zhang X, Zhang H \& Zhou G 2013 Overexpression of CARM1 in breast cancer is correlated with poorly characterized clinicopathologic parameters and molecular subtypes. Diagnostic Pathology 8 129. (https://doi.org/10.1186/1746-1596-8-129)

Chiang K \& Davies CC 2018 Linking PRMT5 to breast cancer stem cells: new therapeutic opportunities? Molecular and Cellular Oncology 5 e1441628. (https://doi.org/10.1080/23723556.2018.1441628)

Chiang K, Zielinska AE, Shaaban AM, Sanchez-Bailon MP, Jarrold J, Clarke TL, Zhang J, Francis A, Jones LJ, Smith S, et al. 2017 PRMT5 is a critical regulator of breast cancer stem cell function via histone methylation and FOXP1 expression. Cell Reports 21 3498-3513. (https://doi.org/10.1016/j.celrep.2017.11.096)

Choi D, Oh KJ, Han HS, Yoon YS, Jung CY, Kim ST \& Koo SH 2012 Protein arginine methyltransferase 1 regulates hepatic glucose production in a FoxO1-dependent manner. Hepatology $\mathbf{5 6}$ 1546-1556. (https://doi.org/10.1002/hep.25809)

Cook JR, Lee JH, Yang ZH, Krause CD, Herth N, Hoffmann R \& Pestka S 2006 FBXO11/PRMT9, a new protein arginine methyltransferase, symmetrically dimethylates arginine residues. Biochemical and Biophysical Research Communications 342 472-481. (https://doi. org/10.1016/j.bbrc.2006.01.167)

Copeland RA 2018 Protein methyltransferase inhibitors as precision cancer therapeutics: a decade of discovery. Philosophical Transactions of the Royal Society of London: Series B, Biological Sciences 373. (https:// doi.org/10.1098/rstb.2017.0080)

Copeland RA, Solomon ME \& Richon VM 2009 Protein methyltransferases as a target class for drug discovery. Nature Reviews Drug Discovery 8 724-732. (https://doi.org/10.1038/nrd2974)
Cuzick J, Sestak I, Baum M, Buzdar A, Howell A, Dowsett M, Forbes JF \& Investigators AL 2010 Effect of anastrozole and tamoxifen as adjuvant treatment for early-stage breast cancer: 10-year analysis of the ATAC trial. Lancet Oncology 11 1135-1141. (https://doi. org/10.1016/S1470-2045(10)70257-6)

Davis MB, Liu X, Wang S, Reeves J, Khramtsov A, Huo D \& Olopade OI 2013 Expression and sub-cellular localization of an epigenetic regulator, co-activator arginine methyltransferase 1 (CARM1), is associated with specific breast cancer subtypes and ethnicity. Molecular Cancer 12 40. (https://doi.org/10.1186/1476-4598-12-40)

Doan TB, Eriksson NA, Graham D, Funder JW, Simpson ER, Kuczek ES, Clyne C, Leedman PJ, Tilley WD, Fuller PJ, et al. 2014 Breast cancer prognosis predicted by nuclear receptor-coregulator networks. Molecular Oncology 8 998-1013. (https://doi.org/10.1016/j. molonc.2014.03.017)

Dowhan DH, Harrison MJ, Eriksson NA, Bailey P, Pearen MA, Fuller PJ, Funder JW, Simpson ER, Leedman PJ, Tilley WD, et al. 2012 Protein arginine methyltransferase 6-dependent gene expression and splicing: association with breast cancer outcomes. Endocrine-Related Cancer 19 509-526. (https://doi.org/10.1530/ERC-12-0100)

Ferlay J, Soerjomataram I, Dikshit R, Eser S, Mathers C, Rebelo M, Parkin DM, Forman D \& Bray F 2015 Cancer incidence and mortality worldwide: sources, methods and major patterns in GLOBOCAN 2012. International Journal of Cancer 136 E359-E386. (https://doi.org/10.1002/ijc.29210)

Gao Y, Zhao Y, Zhang J, Lu Y, Liu X, Geng P, Huang B, Zhang Y \& Lu J 2016 The dual function of PRMT1 in modulating epithelialmesenchymal transition and cellular senescence in breast cancer cells through regulation of ZEB1. Scientific Reports 6 19874. (https:// doi.org/10.1038/srep19874)

Gao WW, Xiao RQ, Zhang WJ, Hu YR, Peng BL, Li WJ, He YH, Shen HF, Ding JC, Huang QX, et al. 2018 JMJD6 licenses ERalpha-dependent enhancer and coding gene activation by modulating the recruitment of the CARM1/MED12 co-activator complex. Molecular Cell 70340. e8-357.e8. (https://doi.org/10.1016/j.molcel.2018.03.006)

Geng P, Zhang Y, Liu X, Zhang N, Liu Y, Liu X, Lin C, Yan X, Li Z, Wang G, et al. 2017 Automethylation of protein arginine methyltransferase 7 and its impact on breast cancer progression. FASEB Journal 31 2287-2300. (https://doi.org/10.1096/fj.201601196R)

Gruber HJ, Mayer C, Meinitzer A, Almer G, Horejsi R, Moller R, Pilz S, Marz W, Gasser R, Truschnig-Wilders M, et al. 2008 Asymmetric dimethylarginine (ADMA) is tightly correlated with growth in juveniles without correlations to obesity related disorders. Experimental and Clinical Endocrinology and Diabetes 116 520-524. (https://doi.org/10.1055/s-2008-1062712)

Gyorffy B, Lanczky A, Eklund AC, Denkert C, Budczies J, Li Q \& Szallasi Z 2010 An online survival analysis tool to rapidly assess the effect of 22,277 genes on breast cancer prognosis using microarray data of 1809 patients. Breast Cancer Research and Treatment 123 725-731. (https://doi.org/10.1007/s10549-009-0674-9)

Habashy HO, Rakha EA, Ellis IO \& Powe DG 2013 The oestrogen receptor coactivator CARM1 has an oncogenic effect and is associated with poor prognosis in breast cancer. Breast Cancer Research and Treatment 140 307-316. (https://doi.org/10.1007/ s10549-013-2614-y)

Hamamoto R \& Nakamura Y 2016 Dysregulation of protein methyltransferases in human cancer: an emerging target class for anticancer therapy. Cancer Science 107 377-384. (https://doi. org/10.1111/cas.12884)

Han HS, Jung CY, Yoon YS, Choi S, Choi D, Kang G, Park KG, Kim ST \& Koo SH 2014 Arginine methylation of CRTC2 is critical in the transcriptional control of hepatic glucose metabolism. Science Signaling 7 ra19. (https://doi.org/10.1126/scisignal.2004479)

Hankinson SE, Willett WC, Manson JE, Colditz GA, Hunter DJ, Spiegelman D, Barbieri RL \& Speizer FE 1998 Plasma sex steroid hormone levels and risk of breast cancer in postmenopausal women. 
Journal of the National Cancer Institute 90 1292-1299. (https://doi. org/10.1093/jnci/90.17.1292)

Harrison MJ, Tang YH \& Dowhan DH 2010 Protein arginine methyltransferase 6 regulates multiple aspects of gene expression. Nucleic Acids Research 38 2201-2216. (https://doi.org/10.1093/nar/ gkp1203)

Hernandez SJ, Dolivo DM \& Dominko T 2017 PRMT8 demonstrates variant-specific expression in cancer cells and correlates with patient survival in breast, ovarian and gastric cancer. Oncology Letters $\mathbf{1 3}$ 1983-1989. (https://doi.org/10.3892/ol.2017.5671)

Hiken JF, Mcdonald JI, Decker KF, Sanchez C, Hoog J, Vanderkraats ND, Jung KL, Akinhanmi M, Rois LE, Ellis MJ, et al. 2017 Epigenetic activation of the prostaglandin receptor EP4 promotes resistance to endocrine therapy for breast cancer. Oncogene 36 2319-2327. (https://doi.org/10.1038/onc.2016.397)

Hong E, Lim Y, Lee E, Oh M \& Kwon D 2012 Tissue-specific and agedependent expression of protein arginine methyltransferases (PRMTs) in male rat tissues. Biogerontology 13 329-336. (https://doi. org/10.1007/s10522-012-9379-2)

Hu D, Gur M, Zhou Z, Gamper A, Hung MC, Fujita N, Lan L, Bahar I \& Wan Y 2015 Interplay between arginine methylation and ubiquitylation regulates KLF4-mediated genome stability and carcinogenesis. Nature Communications 6 8419. (https://doi. org/10.1038/ncomms9419)

Hu H, Qian K, Ho MC \& Zheng YG 2016 Small molecule inhibitors of protein arginine methyltransferases. Expert Opinion on Investigational Drugs 25 335-358. (https://doi.org/10.1517/13543784.2016.1144747)

Jemal A, Bray F, Center MM, Ferlay J, Ward E \& Forman D 2011 Global cancer statistics. CA: A Cancer Journal for Clinicians 61 69-90. (https://doi.org/10.3322/caac.20107)

Jeselsohn R, Cornwell M, Pun M, Buchwalter G, Nguyen M, Bango C, Huang Y, Kuang Y, Paweletz C, Fu X, et al. 2017 Embryonic transcription factor SOX9 drives breast cancer endocrine resistance. PNAS 114 E4482-E4491. (https://doi.org/10.1073/pnas.1620993114)

Jiang W \& Newsham IF 2006 The tumor suppressor DAL-1/4.1B and protein methylation cooperate in inducing apoptosis in MCF-7 breast cancer cells. Molecular Cancer 5 4. (https://doi. org/10.1186/1476-4598-5-4)

Jiang H, Zhou Z, Jin S, Xu K, Zhang H, Xu J, Sun Q, Wang J \& Xu J 2018 PRMT9 promotes hepatocellular carcinoma invasion and metastasis via activating PI3K/Akt/GSK-3beta/Snail signaling. Cancer Science 109 1414-1427. (https://doi.org/10.1111/cas.13598)

Kaniskan HÜ \& Jin J 2017 Recent progress in developing selective inhibitors of protein methyltransferases. Current Opinion in Chemical Biology 39 100-108. (https://doi.org/10.1016/j.cbpa.2017.06.013)

Kleinschmidt MA, De Graaf P, Van Teeffelen HA \& Timmers HTM 2012 Cell cycle regulation by the PRMT6 arginine methyltransferase through repression of cyclin-dependent kinase inhibitors. PLOS ONE 7 e41446. (https://doi.org/10.1371/journal.pone.0041446)

Knight WA, Livingston RB, Gregory EJ \& Mcguire WL 1977 Estrogen receptor as an independent prognostic factor for early recurrence in breast cancer. Cancer Research 37 4669-4671.

Lai Y, Song M, Hakala K, Weintraub ST \& Shiio Y 2011 Proteomic dissection of the von Hippel-Lindau (VHL) interactome. Journal of Proteome Research 10 5175-5182. (https://doi.org/10.1021/pr200642c)

Lakhani SR, International Agency for Research on Cancer \& WHO 2012 WHO Classification of Tumours of the Breast. France, Lyon: International Agency for Research on Cancer.

Le Romancer M, Treilleux I, Leconte N, Robin-Lespinasse Y, Sentis S, Bouchekioua-Bouzaghou K, Goddard S, Gobert-Gosse S \& Corbo L 2008 Regulation of estrogen rapid signaling through arginine methylation by PRMT1. Molecular Cell 31 212-221. (https://doi. org/10.1016/j.molcel.2008.05.025)

Lee JH, Cook JR, Yang ZH, Mirochnitchenko O, Gunderson SI, Felix AM, Herth N, Hoffmann R \& Pestka S 2005 PRMT7, a new protein arginine methyltransferase that synthesizes symmetric dimethylarginine. Journal of Biological Chemistry 280 3656-3664. (https://doi.org/10.1074/jbc.M405295200)

Lee JH, Park GH, Lee YK \& Park JH 2011 Changes in the arginine methylation of organ proteins during the development of diabetes mellitus. Diabetes Research and Clinical Practice 94 111-118. (https:// doi.org/10.1016/j.diabres.2011.07.005)

Li Y, Chitnis N, Nakagawa H, Kita Y, Natsugoe S, Yang Y, Li Z, Wasik M, Klein-Szanto AJ, Rustgi AK, et al. 2015 PRMT5 is required for lymphomagenesis triggered by multiple oncogenic drivers. Cancer Discovery 5 288-303. (https://doi.org/10.1158/2159-8290.CD-140625)

Lonard DM \& O'Malley BW 2012 Nuclear receptor coregulators: modulators of pathology and therapeutic targets. Nature Reviews Endocrinology 8 598-604. (https://doi.org/10.1038/nrendo.2012.100)

Louie MC, Zou JX, Rabinovich A \& Chen HW 2004 ACTR/AIB1 functions as an E2F1 coactivator to promote breast cancer cell proliferation and antiestrogen resistance. Molecular and Cellular Biology 24 5157-5171. (https://doi.org/10.1128/MCB.24.12.51575171.2004)

Love RR \& Philips J 2002 Oophorectomy for breast cancer: history revisited. Journal of the National Cancer Institute 94 1433-1434. (https://doi.org/10.1093/jnci/94.19.1433)

Maas R, Boger R \& Luneburg N 2009 ADMA and the role of the genes: lessons from genetically modified animals and human gene polymorphisms. Pharmacological Research 60 475-480. (https://doi. org/10.1016/j.phrs.2009.07.012)

Masood S 2016 Breast cancer subtypes: morphologic and biologic characterization. Women's Health 12 103-119. (https://doi. $\operatorname{org} / 10.2217 /$ whe.15.99)

Mathioudaki K, Scorilas A, Ardavanis A, Lymberi P, Tsiambas E, Devetzi M, Apostolaki A \& Talieri M 2011 Clinical evaluation of PRMT1 gene expression in breast cancer. Tumour Biology 32 575-582. (https://doi.org/10.1007/s13277-010-0153-2)

Matsuguma K, Ueda S, Yamagishi S, Matsumoto Y, Kaneyuki U, Shibata R, Fujimura T, Matsuoka H, Kimoto M, Kato S, et al. 2006 Molecular mechanism for elevation of asymmetric dimethylarginine and its role for hypertension in chronic kidney disease. Journal of the American Society of Nephrology 17 2176-2183. (https://doi. org/10.1681/ASN.2005121379)

Meyer R, Wolf SS \& Obendorf M 2007 PRMT2, a member of the protein arginine methyltransferase family, is a coactivator of the androgen receptor. Journal of Steroid Biochemistry and Molecular Biology 107 1-14. (https://doi.org/10.1016/j.jsbmb.2007.05.006)

Mitchell LH, Drew AE, Ribich SA, Rioux N, Swinger KK, Jacques SL, Lingaraj T, Boriack-Sjodin PA, Waters NJ, Wigle TJ, et al. 2015 Aryl pyrazoles as potent inhibitors of arginine methyltransferases: identification of the first PRMT6 tool compound. ACS Medicinal Chemistry Letters 6 655-659. (https://doi.org/10.1021/ acsmedchemlett.5b00071)

Morales Y, Caceres T, May K \& Hevel JM 2016 Biochemistry and regulation of the protein arginine methyltransferases (PRMTs). Archives of Biochemistry and Biophysics 590 138-152. (https://doi org/10.1016/j.abb.2015.11.030)

Morettin A, Baldwin RM \& Cote J 2015 Arginine methyltransferases as novel therapeutic targets for breast cancer. Mutagenesis 30 177-189. (https://doi.org/10.1093/mutage/geu039)

Muscat GE, Eriksson NA, Byth K, Loi S, Graham D, Jindal S, Davis MJ, Clyne C, Funder JW, Simpson ER, et al. 2013 Research resource: nuclear receptors as transcriptome: discriminant and prognostic value in breast cancer. Molecular Endocrinology 27 350-365. (https:// doi.org/10.1210/me.2012-1265)

Nakakido M, Deng Z, Suzuki T, Dohmae N, Nakamura Y \& Hamamoto R 2015 PRMT6 increases cytoplasmic localization of p21CDKN1A in cancer cells through arginine methylation and makes more resistant to cytotoxic agents. Oncotarget 6 30957-30967. (https://doi. org/10.18632/oncotarget.5143) 
Neault M, Mallette Fa, Vogel G, Michaud-Levesque J \& Richard S 2012 Ablation of PRMT6 reveals a role as a negative transcriptional regulator of the p53 tumor suppressor. Nucleic Acids Research 40 9513-9521. (https://doi.org/10.1093/nar/gks764)

OECD 2011 Health at a Glance 2011: OECD Indicators. (Online). OECD Publishing. (available at: http://dx.doi.org/10.1787/health_glance2011-en)

Oh TG, Bailey P, Dray E, Smith AG, Goode J, Eriksson N, Funder JW, Fuller PJ, Simpson ER, Tilley WD, et al. 2014 PRMT2 and RORgamma expression are associated with breast cancer survival outcomes. Molecular Endocrinology 28 1166-1185. (https://doi.org/10.1210/ me.2013-1403)

Oh TG, Wang SM, Acharya BR, Goode JM, Graham JD, Clarke CL, Yap AS \& Muscat GEO 2016 The nuclear receptor, RORgamma, regulates pathways necessary for breast cancer metastasis. EBioMedicine 6 59-72. (https://doi.org/10.1016/j.ebiom.2016.02.028)

Oh TG, Wang SM \& Muscat GE 2017 Therapeutic implications of epigenetic signaling in breast cancer. Endocrinology 158 431-447. (https://doi.org/10.1210/en.2016-1716)

Oosterwijk JC, De Vries J, Mourits MJ \& De Bock GH 2014 Genetic testing and familial implications in breast-ovarian cancer families. Maturitas 78 252-257. (https://doi.org/10.1016/j. maturitas.2014.05.002)

Peng C \& Wong CC 2017 The story of protein arginine methylation: characterization, regulation, and function. Expert Review of Proteomics 14 157-170. (https://doi.org/10.1080/14789450.2017.1275573)

Perou CM, Sorlie T, Eisen MB, Van De Rijn M, Jeffrey SS, Rees CA, Pollack JR, Ross DT, Johnsen H, Akslen LA, et al. 2000 Molecular portraits of human breast tumours. Nature 406 747-752. (https://doi. org/10.1038/35021093)

Phalke S, Mzoughi S, Bezzi M, Jennifer N, Mok WC, Low DH, Thike AA Kuznetsov VA, Tan PH, Voorhoeve PM, et al. 2012 p53-Independent regulation of p21WAF1/Cip1 expression and senescence by PRMT6. Nucleic Acids Research 40 9534-9542. (https://doi.org/10.1093/nar/ gks858)

Poulard C, Corbo L \& Le Romancer M 2016 Protein arginine methylation/demethylation and cancer. Oncotarget 7 67532-67550. (https://doi.org/10.18632/oncotarget.11376)

Powers MA, Fay MM, Factor RE, Welm AL \& Ullman KS 2011 Protein arginine methyltransferase 5 accelerates tumor growth by arginine methylation of the tumor suppressor programmed cell death 4 . Cancer Research 71 5579-5587. (https://doi.org/10.1158/0008-5472. CAN-11-0458)

Puchau B, Hermsdorff HH, Zulet MA \& Martinez JA 2009 DDAH2 mRNA expression is inversely associated with some cardiovascular riskrelated features in healthy young adults. Disease Markers 27 37-44. (https://doi.org/10.3233/DMA-2009-0650)

Qi C, Chang J, Zhu Y, Yeldandi AV, Rao SM \& Zhu YJ 2002 Identification of protein arginine methyltransferase 2 as a coactivator for estrogen receptor alpha. Journal of Biological Chemistry 277 28624-28630. (https://doi.org/10.1074/jbc.M201053200)

Raposo AE \& Piller SC 2018 Protein arginine methylation: an emerging regulator of the cell cycle. Cell Division 13 3. (https://doi. org/10.1186/s13008-018-0036-2)

Richon VM, Johnston D, Sneeringer CJ, Jin L, Majer CR, Elliston K, Jerva LF, Scott MP \& Copeland RA 2011 Chemogenetic analysis of human protein methyltransferases. Chemical Biology and Drug Design 78 199-210. (https://doi.org/10.1111/j.1747-0285.2011.01135.x)

Rochette L, Lorin J, Zeller M, Guilland Jc, Lorgis L, Cottin Y \& Vergely C 2013 Nitric oxide synthase inhibition and oxidative stress in cardiovascular diseases: possible therapeutic targets? Pharmacology and Therapeutics 140 239-257. (https://doi.org/10.1016/j. pharmthera.2013.07.004)

Russo J \& Russo IH 2006 The role of estrogen in the initiation of breast cancer. Journal of Steroid Biochemistry and Molecular Biology 102 89-96. (https://doi.org/10.1016/j.jsbmb.2006.09.004)
Sack JS, Thieffine S, Bandiera T, Fasolini M, Duke GJ, Jayaraman L, Kish KF, Klei HE, Purandare AV, Rosettani P, et al. 2011 Structural basis for CARM1 inhibition by indole and pyrazole inhibitors. Biochemical Journal 436 331-339. (https://doi.org/10.1042/ BJ20102161)

Scalera F, Fulge B, Martens-Lobenhoffer J, Heimburg A \& Bode-Boger SM 2009 Red wine decreases asymmetric dimethylarginine via SIRT1 induction in human endothelial cells. Biochemical and Biophysical Research Communications 390 703-709. (https://doi.org/10.1016/j. bbrc.2009.10.033)

Schapira M \& Ferreira de Freitas R 2014 Structural biology and chemistry of protein arginine methyltransferases. MedChemComm 5 1779-1788. (https://doi.org/10.1039/c4md00269e)

Sharma P, Bhattacharyya DK \& Kalita J 2017 Disease biomarker identification from gene network modules for metastasized breast cancer. Scientific Reports 7 1072. (https://doi.org/10.1038/s41598-01700996-x)

Shen Y, Szewczyk MM, Eram MS, Smil D, Kaniskan HÜ, De Freitas RF, Senisterra G, Li F, Schapira M, Brown PJ, et al. 2016 Discovery of a potent, selective, and cell-active dual inhibitor of protein arginine methyltransferase 4 and protein arginine methyltransferase 6 . Journal of Medicinal Chemistry 59 9124-9139. (https://doi.org/10.1021/acs. jmedchem.6b01033)

Shen Y, Zhong J, Liu J, Liu K, Zhao J, Xu T, Zeng T, Li Z, Chen Y, Ding W, et al. 2018 Protein arginine N-methyltransferase 2 reverses tamoxifen resistance in breast cancer cells through suppression of ER-alpha36. Oncology Reports 39 2604-2612. (https://doi.org/10.3892/ or.2018.6350)

Shia WJ, Okumura AJ, Yan M, Sarkeshik A, Lo MC, Matsuura S, Komeno Y, Zhao X, Nimer SD, Yates JR, et al. 2012 PRMT1 interacts with AML1-ETO to promote its transcriptional activation and progenitor cell proliferative potential. Blood 119 4953-4962. (https:// doi.org/10.1182/blood-2011-04-347476)

Shlensky D, Mirrielees JA, Zhao Z, Wang L, Mahajan A, Yu M, Sherer NM, Wilke LG \& Xu W 2015 Differential CARM1 isoform expression in subcellular compartments and among malignant and benign breast tumors. PLOS ONE 10 e0128143. (https://doi. org/10.1371/journal.pone.0128143)

Singh V, Miranda TB, Jiang W, Frankel A, Roemer ME, Robb VA, Gutmann DH, Herschman HR, Clarke S \& Newsham IF 2004 DAL1/4.1B tumor suppressor interacts with protein arginine N-methyltransferase 3 (PRMT3) and inhibits its ability to methylate substrates in vitro and in vivo. Oncogene 23 7761-7771. (https://doi. org/10.1038/sj.onc.1208057)

Sohail M \& Xie J 2015 Evolutionary emergence of a novel splice variant with an opposite effect on the cell cycle. Molecular and Cellular Biology 35 2203-2214. (https://doi.org/10.1128/MCB.00190-15)

Stein C, Riedl S, Ruthnick D, Notzold RR \& Bauer UM 2012 The arginine methyltransferase PRMT6 regulates cell proliferation and senescence through transcriptional repression of tumor suppressor genes. Nucleic Acids Research 40 9522-9533. (https://doi.org/10.1093/nar/gks767)

Stender JD, Nwachukwu JC, Kastrati I, Kim Y, Strid T, Yakir M, Srinivasan S, Nowak J, Izard T, Rangarajan ES, et al. 2017 Structural and molecular mechanisms of cytokine-mediated endocrine resistance in human breast cancer cells. Molecular Cell 65 1122-1135. e5. (https://doi.org/10.1016/j.molcel.2017.02.008)

Swiercz R, Person MD \& Bedford MT 2005 Ribosomal protein S2 is a substrate for mammalian PRMT3 (protein arginine methyltransferase 3). Biochemical Journal 386 85-91. (https://doi.org/10.1042/ BJ20041466)

Swiercz R, Cheng D, Kim D \& Bedford MT 2007 Ribosomal protein rpS2 is hypomethylated in PRMT3-deficient mice. Journal of Biological Chemistry 282 16917-16923. (https://doi.org/10.1074/jbc. M609778200)

Tang P \& Tse GM 2016 Immunohistochemical surrogates for molecular classification of breast carcinoma: a 2015 update. Archives of 
Pathology and Laboratory Medicine 140 806-814. (https://doi. org/10.5858/arpa.2015-0133-RA)

Tang J, Frankel A, Cook RJ, Kim S, Paik WK, Williams KR, Clarke S \& Herschman HR 2000 PRMT1 is the predominant type I protein arginine methyltransferase in mammalian cells. Journal of Biological Chemistry 275 7723-7730. (https://doi.org/10.1074/jbc.275.11.7723)

Teyssier C, Le Romancer M, Sentis S, Jalaguier S, Corbo L \& Cavailles V 2010 Protein arginine methylation in estrogen signaling and estrogen-related cancers. Trends in Endocrinology and Metabolism 21 181-189. (https://doi.org/10.1016/j.tem.2009.11.002)

Thomassen M, Tan Q \& Kruse TA 2009 Gene expression meta-analysis identifies chromosomal regions and candidate genes involved in breast cancer metastasis. Breast Cancer Research and Treatment 113 239-249. (https://doi.org/10.1007/s10549-008-9927-2)

Torre LA, Bray F, Siegel RL, Ferlay J, Lortet-Tieulent J \& Jemal A 2015 Global cancer statistics, 2012. CA: A Cancer Journal for Clinicians 65 87-108. (https://doi.org/10.3322/caac.21262)

Veland N, Hardikar S, Zhong Y, Gayatri S, Dan J, Strahl BD, Rothbart SB, Bedford MT \& Chen T 2017 The arginine methyltransferase PRMT6 regulates DNA methylation and contributes to global DNA hypomethylation in cancer. Cell Reports 21 3390-3397. (https://doi. org/10.1016/j.celrep.2017.11.082)

Wang L, Zhao Z, Meyer MB, Saha S, Yu M, Guo A, Wisinski KB, Huang W, Cai W, Pike JW, et al. 2014 CARM1 methylates chromatin remodeling factor BAF155 to enhance tumor progression and metastasis. Cancer Cell 25 21-36. (https://doi.org/10.1016/j. ccr.2013.12.007)

Wang Z, Kong J, Wu Y, Zhang J, Wang T, Li N, Fan J, Wang H, Zhang J \& Ling R 2018 PRMT5 determines the sensitivity to chemotherapeutics by governing stemness in breast cancer. Breast Cancer Research and Treatment 168 531-542. (https://doi.org/10.1007/ s10549-017-4597-6)

Wu T, Millar H, Gaffney D, Beke L, Mannens G, Vinken P, Sommers I, Thuring J, Sun W, Moy C, et al. 2018 JNJ-64619178, a selective and pseudo-irreversible PRMT5 inhibitor with potent in vitro and in vivo activity, demonstrated in several lung cancer models. In Proceedings of the American Association for Cancer Research Annual Meeting, p 4859. Chicago, IL: Philadelphia Cancer Research.

Yang Y \& Bedford MT 2013 Protein arginine methyltransferases and cancer. Nature Reviews Cancer 13 37-50. (https://doi.org/10.1038/nrc3409)

Yang F, Wang J, Ren Hy, Jin J, Wang Al, Sun LL, Diao KX, Wang EH \& Mi XY 2015a Proliferative role of TRAF4 in breast cancer by upregulating PRMT5 nuclear expression. Tumour Biology 36 5901-5911. (https://doi.org/10.1007/s13277-015-3262-0)

Yang Y, Hadjikyriacou A, Xia Z, Gayatri S, Kim D, Zurita-Lopez C, Kelly R, Guo A, Li W, Clarke SG, et al. $2015 b$ PRMT9 is a type II methyltransferase that methylates the splicing factor SAP145. Nature Communication 66428.

Yao R, Jiang H, Ma Y, Wang L, Wang L, Du J, Hou P, Gao Y, Zhao L, Wang G, et al. 2014 PRMT7 induces epithelial-to-mesenchymal transition and promotes metastasis in breast cancer. Cancer Research 74 5656-5667. (https://doi.org/10.1158/0008-5472.CAN-14-0800)

Yoshimatsu M, Toyokawa G, Hayami S, Unoki M, Tsunoda T, Field HI, Kelly JD, Neal DE, Maehara Y, Ponder BA, et al. 2011 Dysregulation of PRMT1 and PRMT6, Type I arginine methyltransferases, is involved in various types of human cancers. International Journal of Cancer 128 562-573. (https://doi.org/10.1002/ijc.25366)

Yoshimoto T, Boehm M, Olive M, Crook MF, San H, Langenickel T \& Nabel EG 2006 The arginine methyltransferase PRMT2 binds RB and regulates E2F function. Experimental Cell Research 312 2040-2053. (https://doi.org/10.1016/j.yexcr.2006.03.001)

Zhong J, Cao RX, Hong T, Yang J, Zu XY, Xiao XH, Liu JH \& Wen GB 2011 Identification and expression analysis of a novel transcript of the human PRMT2 gene resulted from alternative polyadenylation in breast cancer. Gene $\mathbf{4 8 7}$ 1-9. (https://doi.org/10.1016/j. gene.2011.06.022)

Zhong J, Cao RX, Zu XY, Hong T, Yang J, Liu L, Xiao XH, Ding WJ, Zhao Q, Liu JH, et al. 2012 Identification and characterization of novel spliced variants of PRMT2 in breast carcinoma. FEBS Journal 279 316-335. (https://doi.org/10.1111/j.1742-4658.2011.08426.x)

Zhong J, Cao RX, Liu JH, Liu YB, Wang J, Liu LP, Chen YJ, Yang J, Zhang QH, Wu Y, et al. 2014 Nuclear loss of protein arginine $\mathrm{N}$-methyltransferase 2 in breast carcinoma is associated with tumor grade and overexpression of cyclin D1 protein. Oncogene $\mathbf{3 3}$ 5546-5558. (https://doi.org/10.1038/onc.2013.500)

Zhong J, Chen YJ, Chen L, Shen YY, Zhang QH, Yang J, Cao RX, Zu XY \& Wen GB 2017 PRMT2beta, a C-terminal splice variant of PRMT2, inhibits the growth of breast cancer cells. Oncology Reports $\mathbf{3 8}$ 1303-1311. (https://doi.org/10.3892/or.2017.5786)

Zurita-Lopez CI, Sandberg T, Kelly R \& Clarke SG 2012 Human protein arginine methyltransferase 7 (PRMT7) is a type III enzyme forming omega-NG-monomethylated arginine residues. Journal of Biological Chemistry 287 7859-7870. (https://doi.org/10.1074/jbc. M111.336271)

Received in final form 11 December 2018

Accepted 7 January 2019

Accepted Preprint published online 7 January 2019 (c) 2019 Society for Endocrinology Published by Bioscientifica Ltd. Printed in Great Britain 